\title{
Arterial desaturation in HIV positive patients undergoing sputum induction
}

\author{
Robert F Miller, Jennifer Buckland, Stephen J G Semple
}

\begin{abstract}
Arterial oxygen saturation $\left(\mathrm{SaO}_{2}\right)$ was monitored continuously during and immediately after sputum induction in 41 HIV positive patients with respiratory symptoms and in 20 symptomless medical and nursing staff, who acted as control subjects. Arterial oxygen desaturation (defined as $\mathrm{SaO}_{2} \leqslant 92 \%$ ) occurred during sputum induction and persisted for up to 20 minutes after the end of the procedure in 11 of the 20 patients with Pneumocystis carinii pneumonia and in nine of the 21 patients with other respiratory diagnoses. None of the control subjects showed oxygen desaturation. Neither the severity of chest radiographic abnormalities, the alveolar-arterial oxygen gradient (both measured before sputum induction), nor baseline $\mathrm{SaO}_{2}$ prospectively identified the patients who developed oxygen desaturation. Two patients, one with pneumocystis pneumonia, developed dyspnoea and had a fall in arterial oxygen saturation to $84 \%$ within 10 minutes of starting sputum induction. The procedure was abandoned in both patients and in two further patients, who developed severe nausea and retching but no oxygen desaturation. Sputum induction in HIV positive patients with respiratory symptoms may induce a fall in $\mathrm{SaO}_{2}$ that persists after this procedure. This may be important if other procedures are performed soon after sputum induction.
\end{abstract}

Sputum induction is being used increasingly to diagnose respiratory pathogens, particularly Pneumocystis carinii, in HIV positive patients presenting with respiratory symptoms. $^{1-3}$ The procedure may be associated with adverse events, including cough, dyspnoea, nausea, and retching, and some patients find the procedure unpleasant. ${ }^{4}$ More serious adverse events include the rapid development of pleural effusions after sputum induction. ${ }^{5}$ In this study we have continuously monitored oxygen saturation while sputum induction was performed in HIV positive patients presenting with acute respiratory episodes and in healthy volunteers.

\section{Methods}

We studied 41 patients presenting with acute respiratory episodes. All were known to be HIV antibody positive or to have a diagnosis of AIDS. Thirty eight were homosexual men, two were female intravenous drug users, and one was a woman who had received an infected blood transfusion. The subjects were aged 23-61 (mean 37) years; 17 were cigarette smokers. These patients were divided into two groups. Group 1 (20 patients) had a diagnosis of Pneumocystis carinii pneumonia, made by sputum induction or subsequent fibreoptic bronchoscopy and bronchoalveolar lavage, or by open lung biopsy after a negative bronchoscopy. Group 2 (21 patients) had an alternative diagnosis made after sputum induction or bronchoalveolar lavage or both or, when these gave negative results, percutaneous or open lung biopsy, or they had had negative results in all investigations, self limiting symptoms, and no need for any treatment. The control group consisted of 20 medical and nursing staff ( 16 men, four women aged 23-64 (mean 32.4) years) with no respiratory symptoms and no risk factors for HIV infection. Six were cigarette smokers.

All patients had a chest radiograph and arterial blood gases were obtained while they were breathing room air to calculate the alveolar-arterial oxygen gradient $\left(\mathrm{A}-\mathrm{aDo}_{2}\right)$ before sputum induction, as part of their routine investigations. The chest radiographs were reviewed together by a radiologist who knew that the patients were HIV positive but was blinded to the study outcome. Radiographic appearances were graded quantitatively on a scale of $0-4$ : grade $0=$ normal; grade $1=$ subtle increased perihilar interstitial markings; grade $2=$ more prominent interstitial markings extending laterally, without evidence of alveolar infiltrates; grade $3=$ gross interstitial disease with mild alveolar infiltrates; grade $4=$ extensive interstitial and alveolar infiltrates. ${ }^{6}$

Sputum induction was carried out with a Devilbliss $99 \mathrm{~m}$ Ultraneb ultrasonic nebuliser (Devilbliss, Feltham). Subjects inhaled 20-30 $\mathrm{ml}$ of $2.7 \%$ saline (Kendall Laboratories, Basingstoke) for 20 minutes while sitting semi-upright. The procedure was supervised throughout by a respiratory physiotherapist. Arterial oxygen saturation was monitored from immediately before the start of sputum induction, throughout the procedure, and for 20 minutes afterwards with a Nellcor $\mathrm{N}-100 \mathrm{E}$ (Nellcor Inc, Hayward, California) oximeter. A finger probe was applied to the nondominant hand.

Data were analysed by means of Wilcoxon's sum rank test within each group. A p value of $<0.05$ was taken to be significant. 


\section{Results}

The diagnoses in the patients in group 2 were cytomegalovirus pneumonitis (1 patient), intrapulmonary lymphoma (1), intrapulmonary Kaposi's sarcoma (1), bacterial pneumonia (3), bronchitis responding to oral erythromycin or amoxycillin (11), self limiting fever and cough with dyspnoea and negative results in investigations (4).

Eleven patients in group 1 (four smokers) showed a fall in $\mathrm{SaO}_{2}$ to $92 \%$ or less (figure, A). One patient had sputum induction discontinued when he became dyspnoeic; the $\mathrm{SaO}_{2}$ had fallen to $84 \%$ within five minutes of the start of the procedure. In the remaining 10 patients, whose $\mathrm{SaO}_{2}$ fell to $92 \%$ or less, the fall usually started five to 10 minutes after the start of the procedure. In two patients the $\mathrm{SaO}_{2}$ began to rise once the procedure was completed but had not returned to baseline 20 minutes later. In the other eight patients a further fall in $\mathrm{SaO}_{2}$ occurred after sputum induction was completed. Four of these patients had mild dyspnoea and an $\mathrm{SaO}_{2}$ of $90 \%$ or less 20 minutes after the end of sputum induction; these patients were then given supplemental oxygen.

Nine patients in group 2 (five smokers) showed a fall in $\mathrm{SaO}_{2}$ to $92 \%$ or less during the procedure; in one sputum induction was discontinued because it fell to $84 \%$ (after 10 minutes' saline inhalation) and the patient was tachypnoeic and dyspnoeic (figure, B). In the remaining eight patients the fall in $\mathrm{SaO}_{2}$ occurred five to 15 minutes after the start of the procedure. It rose promptly in one patient but in the other seven it fell further after the end of the procedure. Three patients, who had an $\mathrm{SaO}_{2}$ of $89 \%$ or less 20 minutes after the procedure, were dyspnoeic and were given oxygen via a face mask. No control subject had an $\mathrm{SaO}_{2}$ of $92 \%$ or less during or after inhalation of hypertonic saline (table).

Neither the severity of chest radiographic abnormalities nor the $\mathrm{A}-\mathrm{aDO}_{2}$ allowed prediction of which patients would develop arterial oxygen desaturation. The range (mean) radiographic score in those who did and did not develop oxygen desaturation was $0-3(1.6)$ and $0-3(1 \cdot 5)$. In group 1 in those that did and did not develop oxygen desaturation the range (mean) $\mathrm{A}-\mathrm{aDo}_{2}$ was $0.3-7.6(4.7)$ and $0.4-5.8$ $(3 \cdot 1) \mathrm{kPa}$; in group 2 the corresponding figures for $\mathrm{A}-\mathrm{aDO}_{2}$ were $0 \cdot 1-7 \cdot 5(3.5)$ and $0 \cdot 1-3.4$ $(1.5) \mathrm{kPa}$.

Sputum induction was abandoned in two other patients from group 2, who developed severe nausea and retching, one vomiting repeatedly; neither patient showed oxygen desaturation. Three patients who continued with the procedure also developed nausea and retching. Other adverse events associated with the procedure were dyspnoea ( 7 patients), and severe intractable cough (4). One patient in group 2 experienced acute bronchoconstriction but with no fall in $\mathrm{SaO}_{2}$. One person in the control group with a history of exercise induced

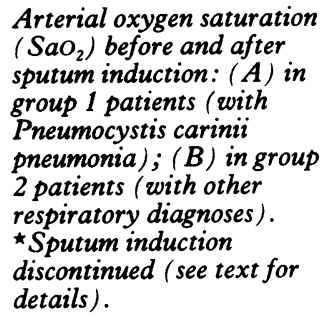

Arterial oxygen saturation
$\left(\mathrm{SaO}_{2}\right)$ before and after

$\mathrm{SaO}_{2}(\%)$

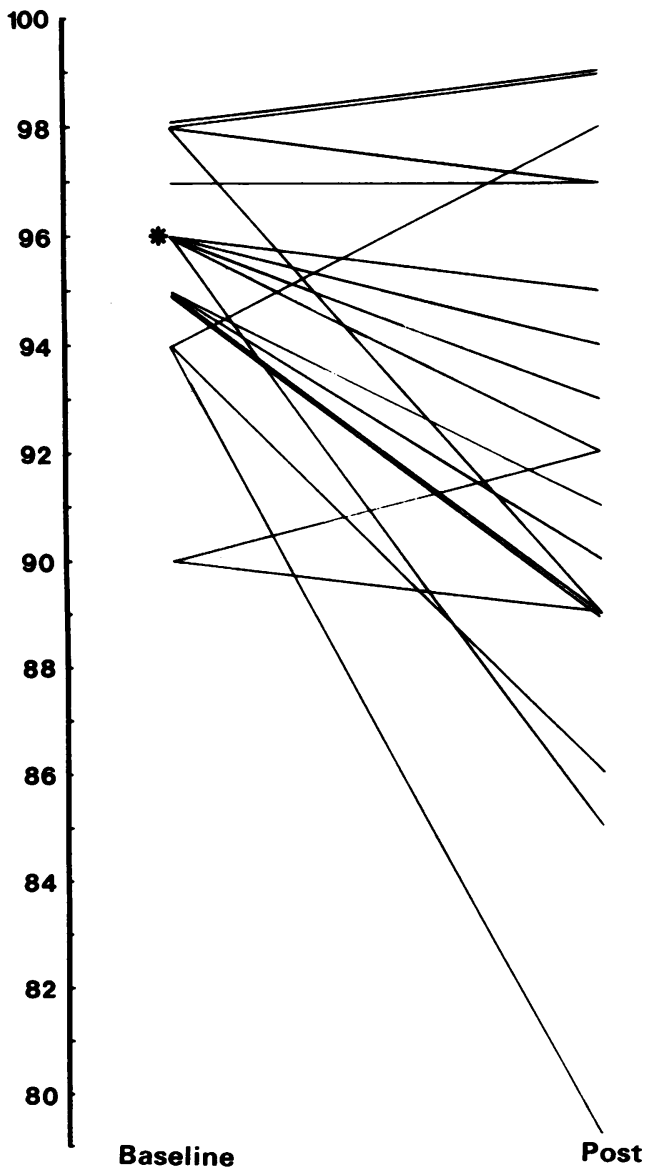

$\mathrm{SaO}_{2}(\%)$

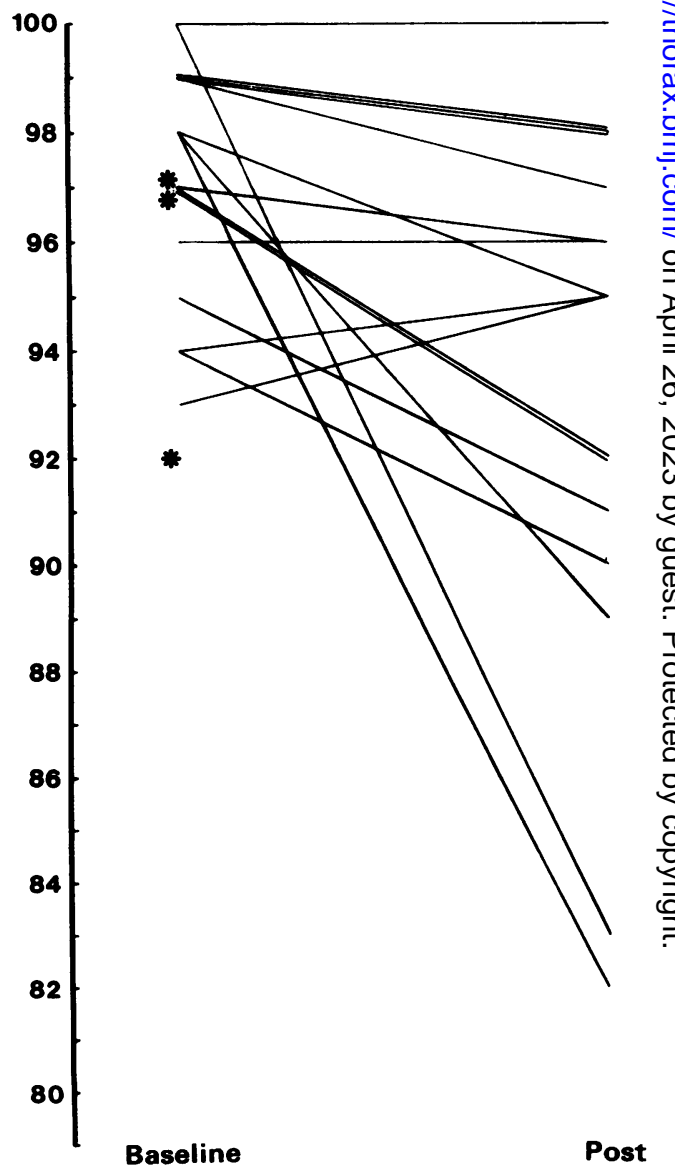


Mean (SE) arterial oxygen saturation during and after sputum induction

\begin{tabular}{|c|c|c|c|c|c|c|}
\hline \multirow[b]{3}{*}{ Group } & \multicolumn{6}{|c|}{ Arterial oxygen saturation (\%) } \\
\hline & \multirow[b]{2}{*}{ Baseline } & \multicolumn{4}{|c|}{ Minutes from start of procedure } & \multirow{2}{*}{$\begin{array}{l}\text { After } \\
\text { procedure }\end{array}$} \\
\hline & & 5 & 10 & 15 & 20 & \\
\hline $\begin{array}{l}\text { Patients with PCP }(n=20) \\
\text { Patients with no PCP }(n=21) \\
\text { Normal subjects }(n=20)\end{array}$ & $\begin{array}{l}95 \cdot 4(0 \cdot 5) \\
97 \cdot 0(0 \cdot 5) \\
97 \cdot 2(0 \cdot 3)\end{array}$ & $\begin{array}{l}93.5(1 \cdot 1) \\
95.6(0 \cdot 8) \\
96.9(0.9)\end{array}$ & $\begin{array}{l}93.7(0.6) \\
95.0(0.8) \\
96.4(0.5)\end{array}$ & $\begin{array}{l}94.2(0.9) \\
95.0(0 \cdot 7) \\
96 \cdot 1(0 \cdot 7)\end{array}$ & $\begin{array}{l}92.7(1.0)^{\star} \\
94.8(0.9)^{\star} \\
96.0(0.5)\end{array}$ & $\begin{array}{l}91 \cdot 7(1 \cdot 1) \dagger \\
93.6(0.9) \dagger \\
96.5(0.5)\end{array}$ \\
\hline
\end{tabular}

${ }^{\star} \mathrm{p}<0.05 ; \mathrm{pp}<0.01$

PCP-Pneumocystis carinii pneumonia.

asthma felt dyspnoeic soon after beginning to inhale saline; his peak flow fell from 610 to $570 \mathrm{l} /$ min but had risen to baseline 30 minutes later.

\section{Discussion}

Inhalation of hypertonic saline during sputum induction in HIV positive patients induced a fall in $\mathrm{SaO}_{2}$ in some patients that persisted after the end of the procedure. It was not possible to predict which patients would develop oxygen desaturation during sputum induction from baseline $\mathrm{SaO}_{2}, \mathrm{~A}-\mathrm{aDO}_{2}$ or severity of chest radiograph changes, and those with the lowest baseline $\mathrm{SaO}_{2}$ did not necessarily have the greatest falls in $\mathrm{SaO}_{2}$. Some patients found the procedure unpleasant. In two cases the rapid fall in $\mathrm{SaO}_{2}$ to below $85 \%$ led us to discontinue sputum induction. We did not measure arterial carbon dioxide tension $\left(\mathrm{PaCO}_{2}\right)$ but there was no clinical evidence of alveolar hypoventilation at any time. The fall in $\mathrm{SaO}_{2}$ is probably due to abnormalities of ventilation-perfusion ratios throughout the lung; this may be caused by deposition of saline in peripheral airways and alveoli. On the assumption of a normal oxygen dissociation curve and a $\mathrm{pH}$ of $7 \cdot 4$, the mean fall in arterial oxygen saturation from $95.4 \%$ to $91.7 \%$ in group 1 represents a fall in $\mathrm{PaO}_{2}$ from 10.3 to $8.3 \mathrm{kPa}$; in group 2 the mean fall from $97 \%$ to $93.6 \%$ represents a fall from $12 \cdot 2$ to $9 \cdot 0$ $\mathrm{kPa}{ }^{7}$

There was virtually no change in arterial oxygen saturation in the control group, which suggests that arterial desaturation occurs only in patients with abnormal lungs. Possibly nonHIV infected patients with pulmonary infection would also show a fall in arterial oxygen saturation during sputum induction; alternatively HIV infection, by producing low grade alveolitis, may predispose to desaturation. ${ }^{8}$

Sputum induction in HIV positive patients was safe in this study and no special supervision is needed if the procedure is carried out in a ward with staff nearby. Patients who are hypoxaemic before sputum induction may require more supervision and $\mathrm{SaO}_{2}$ monitoring may be useful during and immediately after the procedure. The persistence of arterial desaturation may be important if other procedures, such as exercise testing (which may induce further desaturation), are carried out soon after sputum induction.

We wish to thank Dr Jonathon Glover for reporting the chest radiographs and Miss Jane Catchpole for typing the manuscript.

1 Bigby TD, Margolskee D, Curtis JL, et al. The usefulness of induced sputum in the diagnosis of Pneumocystis carini pneumonia in patients with the acquired immunodeficiency syndrome. Am Rev Respir Dis 1986;133:515-8.

2 Leigh TR, Parsons P, Hume C, Husain OAN, Gazzard B, Collins JV. Sputum induction for diagnosis of Pneumocys tis carinii pneumonia. Lancet 1990;ii:205-6.

3 Zaman MK, Wooten OJ, Suprahmanya B, Ankobiah W, Finch PJP, Kamholz SL. Rapid non-invasive diagnosis of Pneumocystis carinii pneumonia from induced liquefied sputum. Ann Intern Med 1988;109:7-10.

4 Miller RF, Semple SJG, Kocjan G. Difficulties with sputum induction for diagnosis of Pneumocystis carinii pneumonia. Lancet 1990;335:112.

5 Nelson M, Bower M, Smith D, Gazzard BG: Life-threatening complication of sputum induction. Lancet 1990; 335:112-3.

6 Brenner M, Ognibene FP, Lack EE, et al. Prognostic factors and life expectancy of patients with acquired immunodeficiency syndrome and Pneumocystis carinii pneumonia. Am Rev Respir Dis 1987;136:1199-206.

7 Cotes JE. Lung function: assessment and application in medicine. 4th ed. Oxford: Blackwell, 1979:218-9.

8 Meignan M, Guillon J-M, Denis M, et al. Increased lung epithelial permeability in HIV-infected patients with isolated cytotoxic T-lymphocytic alveolitis. $A m R e v$ Respir Dis 1990;141:1241-8. 